\title{
Trade Competitiveness of Tea from Fujian, China: Analysis based on Porter Masonry Model
}

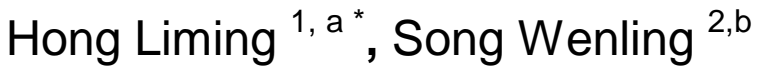 \\ ${ }^{1}$ School of Business, Xiamen University of Technology, \\ Xiamen, 361024, China \\ ${ }^{2}$ School of Business, Xiamen University of Technology, \\ Xiamen, 361024, China \\ a liminghong@xmut.edu.cn, b $1134217540 @ q q . c o m$
}

\begin{abstract}
Keywords: Fujian tea; Trade Competitiveness; Porter masonry model; The international market share. Abstract. Tea sales to more than sixty countries or regions and bring about foreign exchange as the pillar industry of Fujian province in China .Therefore qualitative and quantitative systematic research on the trade competitiveness of Fujian tea is important. We employed Porter masonry model to analyze the six major factors of tea export in Fujian, then estimated the export competitiveness level of Fujian tea by some commonly used quantitative indicators such as international market share. Finally we derived some constructive strategy.
\end{abstract}

\section{Introduction}

Tea is favored for healthy and cultural implications as one of the three drinks in the world. China is the birthplace of tea and has vast production area, in which Fujian ranked first and its tea exports volume increased to 15,000 tons with the value of 110 million US dollars and the average export price of $\$ 6.9 / \mathrm{kg}$ in 2013 . However in post-crisis era Chinese tea is facing fierce international competition. The systematic research on the international competitiveness of Fujian tea would help promote the export of Fujian tea and provide experience for other tea-producing province in China.

Most literature cover the history and present situation of the tea trade, factors, international market and countermeasures to enhance tea competitiveness. International research mainly come from Japan and generally describe the domain development and factors of tea [1,2].The trade research focus on consumer preferences and marketing strategies[1,3] and few referred to the current international environment[4].Chinese scholars concentrate the tea industry of China and ignore the regional tea industry in the international market, most of which is qualitatively and short of quantitative and in-depth analysis of export competitiveness[5,6]. This paper combined theoretical models and quantitative analysis , and employed Porter masonry model and export competitiveness indicators to study the international competitiveness and factors of Fujian tea

\section{Development of Fujian Tea in Domestic and International Market}

Chinese tea develop rapidly with domestic garden area of 2280 thousand hectares and output of 1.79 million tons in 2012, in which Fujian accounted for $9.71 \%$ of national garden area, $17.93 \%$ of national tea output with gross output value up to 15 billion yuan, leading in several major tea-producing provinces. Oolong, black and green tea comprise three main Fujian tea and oolong tea account for $86.5 \%$ of national production.

Fujian tea have played an important role in the international market since the ban on maritime trade policy was lifted late 1870 s and the export production and price increase recently. In 2013 Fujian tea export amounted to 15,000 tons with an increase of $4.8 \%$, the export value amount to $\$ 110$ million with an increase of $25 \%$, and the average export price was $\$ 6.9 / \mathrm{kg}$, up about $19 \%$

Exports market concentrate Japan, Hong Kong, the United States, the European Union and the ASEAN countries and account for more than $90 \%$ of the provincial exports, in which the export to 
Japan account for $60 \%$ for many years in spite of Sino-Japanese political relations[6]. In 2013 the export volume to Japan, ASEAN and America respectively amount to 8802 tons, 1161 tons and 1027 tons with an increase of $15.7 \%, 47.4 \%$ and $-6.9 \%$ and respectively account for $57.8 \%, 7.6 \%$ and $20 \%$ of provincial export. 20\% of green tea and scented tea sales to Hong Kong and 10\%-15\% of black tea to Europe, America and ASEAN, and Singapore, Malaysia, Thailand and Africa are prospective [7].

The rise of China trigger concerns of trading partners and green technical barriers are used to limit agricultural imports from China, especially tea pesticide maximum residue levels (MRLS).In addition to increasingly stringent Japanese MRLS standards, EU MRLS is strict, complicated and changeable which rise from 7 in 1999 to 108 in 2000 and then increase to 289 in 2008 and 400 in 2010[8].That make Fujian tea passive and undermine its trade competitiveness. Furthermore Fujian tea face anti-dumping and the challenges from emerging countries.

In a word, Fujian tea industry is prospective with steady growth in international market demand and implications of tea culture while need to improve trade competitiveness in the fierce international competition as the main tea-producing province in China.

\section{Export Competitiveness of Fujian Tea from the Perspective of Porter Masonry Model}

Porter masonry model is commonly used to study international competitiveness of domestic industry and factors which consist of four basic factors and two secondary factors including production factor, demand conditions, related and supporting industry conditions, corporate strategy and competitor , government and opportunity. These factors interplay and constitute organic systems.

Factors of production cover natural resources, human resources, knowledge resources, capital resources and infrastructure. The natural resource of Fujian is appropriate for tea. The province mostly locate in the subtropical and is abundant of heat and rainfall .The land area amount to $124 \mathrm{~km}^{2}, 80 \%$ of which is suitable for tea cultivation despite natural disasters[9]. The labor of Fujian is up to 2555.86 million, $55.8 \%$ of which is rural and supply abundant human resources for tea production. Fujian tea farmers are experienced while the wage is moderate in the main tea-producing provinces in China, which are shown in Table 1. Therefore Fujian is suitable for labor-intensive tea production.

Table 1 Average Annual Wage from Major Tea Provinces in China in 2012

\begin{tabular}{llllccccc}
\hline Province & Fujian & Anhui & Zhejiang & Sichuan & Hubei & Hunan & Yunan & Guizhou \\
\hline $\begin{array}{l}\text { Annual } \\
\text { wage[RMB: }\end{array}$ \\
\begin{tabular}{l} 
yuan]] \\
\hline
\end{tabular} Note: Information on http://data.stats.gov.cn/workspace/index?m=fsnd & 22845 & 41718 & 31430 & 23039 & 20624 & 21232 & 20850 \\
\end{tabular}

Tea related and supporting industries constitute of the upstream chain supplying raw materials and technology such as tea base, agricultural technology and the end chain providing processing, manufacturing and service such as tea processing, tea culture, sales channels, etc., First, Most tea base lies in industrial clusters or export base. Fujian tea base include Fujian Tea Import and Export Company Limited (Fu tea company), Fujian Anxi eight horses tea industry and Huaxiangyuan tea industry, especially $\mathrm{Fu}$ tea company has four tea bases and provide strong industrial support for tea selection, breeding, harvesting, storage and so on. Second, Agricultural technology covers cultivation, irrigation, fertilization, usage of machinery, harvesting techniques and modern tea production. Fu Tea Company establish 38,000 acres of organic tea plantation in which the atmosphere, soil and water are in line with green food standards, sound inspection system and quality management system are set up to full monitor the whole projects(raw materials, finished tea, tea physics and chemistry, microbiology and pesticide residues and so on).The jasmine tea and oolong tea export from Fu tea company lead in domestic companies. However, most business is difficult to achieve high quality standards limited by technology and funds. Third, extraction from tea leaves are processed to tea polyphenols and pigments, which extend the tea industry chain and improve resource comprehensive utilization. Recently Fujian 
tea create pure Wuyi tea, concentrated fruit juice and other tea drinks from tea processing and enter the European market. Fourth, culture cover tea culture tourism, tea ceremony and so on. The tourism projects rise and is famous overseas after the success of Impression Dahongpao by Zhang Yimou. Many provincial tea companies hold traveling tea art performances and exhibitions around tea-importing countries to promote tea export. Fifth, Fujian high-grade tea sales mainly through supermarkets and specialty stores in domestic market while the subsidiaries and branches directly in the exporting country or trade agency indirectly such as international tea fair, web and phone promotion in the international market .

Fujian tea companies employ brand-building strategy to cultivate first-class international brands while subject to production decentralization by tea farmers, backward technology and equipment. International competitors including Kenya, Sri Lanka and India dominate the global tea market with efficient resource utilization, mechanization, innovation management and government support. Particularly Kenya develop to be most important producer of black tea with short history.

Local government in Fujian play an important role and formulate the first tea industry local laws and regulations" The regulation to promote tea industry in Fujian" in 2012 and "Six measures to modernize tea industry" in 2014.Provincial Department of Finance and Agriculture support tea brand building.for example, the leading companies which enter counseling period on the stock market could get one-time financial incentives of one million yuan. Furthermore Fujian government encourage tea enterprises and farmers cooperatives to carry out tea electronic mall and expand domestic and foreign markets while the supervision over tea production and marketing process need promotion.

Reform and opening up is the first opportunity for Fujian tea after the founding of New China. Fujian tea develop rapidly through "Tea Project" and rank first in the country for eight consecutive years with the production more than 100000 tons from 1996.China joined WTO in2001 and promote tea and its processing derivatives, culture to spread overseas and the international competitiveness. With the arrival of post-crisis era the export of Fujian tea have gradually restored from the world financial crisis in 2008. Meanwhile three Fujian tea including Fuding white tea, Anxi tieguanyin tea, Wuyishan Dahongpao tea is nominated "Tea expo 10 from China".

\section{The quantitative estimators on export competitiveness of Fujian tea}

International market share of Chinese tea stayed 13\% between Kenya and India during 2002-2012 which increased slightly during 2010-2012 and exceed Kenya to rank second in the world. The results are shown in Figure 1[10], similarly Fujian tea.

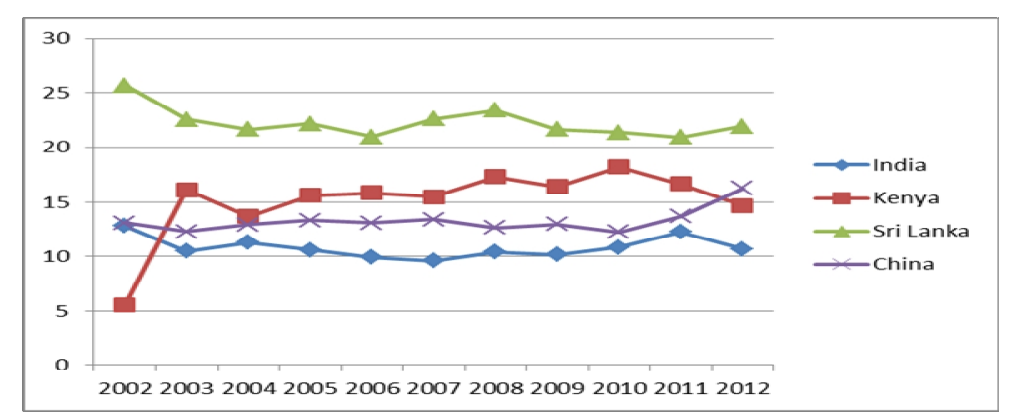

Figure 1 The international market share of the main tea exporting countries during 2002-2012 [unit:\%]

The international market price of tea is tea export value divided by annual export volume.The international market price of Fujian tea is higher than domestic price and four major tea exporting countries before 2007, especially 50\% higher than Kenya. It fell from $\$ 2.89 / \mathrm{kg}$ to $\$ 2.29 / \mathrm{kg}$ after the international financial crisis in 2008 which is lower than international competitors and equally to the national average level while quickly rebounded as much as twice price of India and topped again in 2011 with the world economic recovery. The results are shown in Figure 2. There is no price advantage for Fujian tea compared with India, Kenya, Sri Lanka. 


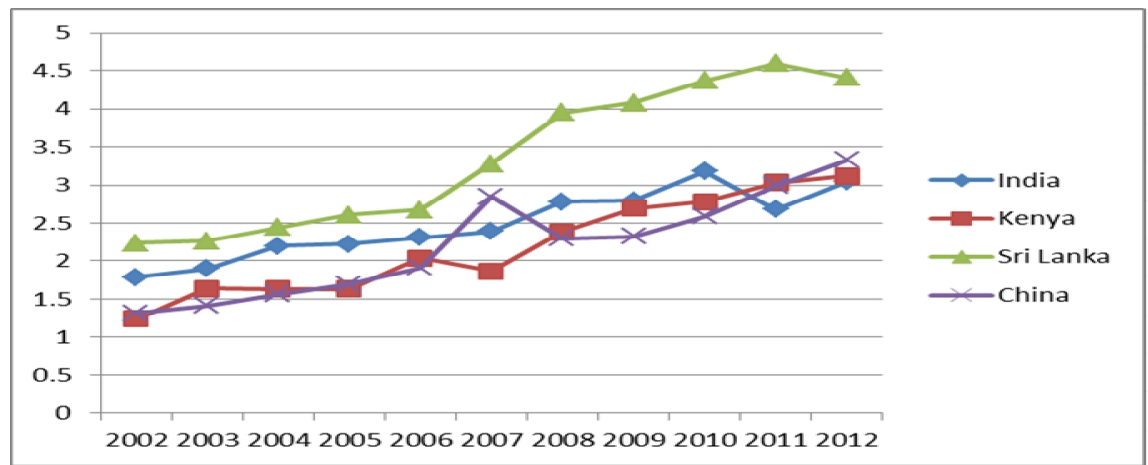

Figure 2 The international market price of tea from major tea exporting countries and Fujian during $2002--2012$ [Unit: USD/kg]

Note: Figure 2 is obtained by calculation based on data from "Fujian Statistical Yearbook" in which values are rounded to two decimal places

Trade competitiveness index (TC) shown in equation (1) means proportion of exports higher and the international competitiveness stronger when TC tends to 1 . In equation(1), E is export of tea and I is import of tea when TC is used to study Trade competitiveness index of Fujian tea.TC of Fujian tea during 2002-2012 is close to 1 and strong, about 1/3 of Fujian tea sale overseas. The results are shown in Table 2.

$\mathrm{TC}=(\mathrm{E}-\mathrm{I}) /(\mathrm{E}+\mathrm{I})$.

Table 2 Trade Competitiveness Index of Fujian Tea during 2002-2012

\begin{tabular}{|c|c|c|c|c|c|c|c|c|c|c|}
\hline Year 2002 & 2003 & 2004 & 2005 & 2006 & 2007 & 2008 & 2009 & 2010 & 2011 & 2012 \\
\hline 0.99 & 0.98 & 0.99 & 0.99 & 0.98 & 1.00 & 0.98 & 0.98 & 0.97 & 0.97 & 0.98 \\
\hline
\end{tabular}

Revealed Comparative Advantage (RCA) is the most authoritative indicator to analyze a country's products in the international market competitiveness as shown in equation(2). It indicate that international competitiveness is very strong, strong, moderate and weak respectively when RCA> $2.5,1.25 \leq \mathrm{RCA}<2.5,0.8 \leq \mathrm{RCA}<1.25$, RCA $<0.8$. The RCA of Fujian tea is higher than 2.5 during 2002-2012 despite the global financial crisis while weakened slightly recently. The results are shown in Table 3.

$$
R C A_{\mathrm{ij}}=\left(X_{i j} / X_{t j}\right) \div\left(X_{i w} / X_{t w}\right) \text {. }
$$

in equation(2) $X_{\mathrm{ij}}$ is export of Fujian tea , $X_{t j}$ is all merchandise exports in Fujian, $X_{i w}$ is all merchandise exports worldwide when used to analyze the international competitiveness of Fujian tea

Table 3 The revealed comparative advantage index of Fujian tea during 2002-2012

\begin{tabular}{|c|c|c|c|c|c|c|c|c|c|c|}
\hline Year 2002 & 2003 & 2004 & 2005 & 2006 & 2007 & 2008 & 2009 & 2010 & 2011 & 2012 \\
\hline RCA 7.48 & 4.38 & 3.59 & 6.99 & 4.39 & 5.69 & 3.71 & 3.05 & 5.38 & 4.16 & 4.96 \\
\hline
\end{tabular}

\section{Conclusion}

The strategy to improve international competitiveness of Fujian tea based on the quantitative and qualitative analysis above is significant. First of all, tea company should establish high quality tea garden base to step over technical and green trade barrier, improve mechanization level to reduce labor costs, implement industrial management to promote international brand building, develop new products and open up new markets and distribution channels. From the macroeconomic level Fujian government should strengthen supervision on tea quality, promote tea industry-university collaboration, provide preferential tax and financing policy, encourage tea enterprises listed and 
trademark registration and so on. Furthermore, Fujian government could bring tea business up during the government visits to promote export with reference to the mode of government and enterprises of Europe and America.

\section{Acknowledgments}

This work is supported by high-level personnel items from Xiamen University of Technology "Trade liberalization, Technological Innovation and Employment"(Item Number :YSK15004R).

\section{References}

[1] Oishi, Sadao, The history of Japanese tea industry, Tokyo Press,3(2004)34-36

[2]B.Radhakrishnan,J.Durairaj,SihyMathew,P.Mohankumar,K.G.Udayabhanu.etal.[J].planters' Chronicle,6(2012):23.

[3] Alastair Hicks.AUJ.T 2009(4):251-264.

[4] P. S. Sundar. Assam Review and Tea News 2012(12):100.

[5] Wenjing Sun, Fang Lan, Education of Fujian Institute of Socialism 2008(4):2-3.In Chinese.

[6] Yongmei $\mathrm{Xu}$, The research on the factor and effects of tea export in China[M] Beijing: China Agriculture Press, 2009 (2): 34-35. In Chinese

[7] Practical information,Chinese tea 2014,3:31-33 In Chinese

[8] Guoxue Wei, Jikun Huang, Jun Yang.China Economic Review,2012( 23):253-264

[9] The research group for the competitiveness of Fujian tea. Fujian tea 2013,1:2-5. In Chinese

[10] Information on http://www.chinairr.org/view/V08/201407/08-159622.html. 